hospitalization will be arranged in serious and emergent cases to begin with. There are proposals to construct a hospital in the Bombay area and also to provide hospital accommodation in the suburban area for insured persons. Till this is done. beds in existing hospitals, both private and Government, have been reserved. Fourthly, specialist services will be available through special centres established in, or run in close association with, the hospitals. Fifthly, ambulances have been provided for the exclusive use of insured persons. Sixthly, women workers will be provided free antenatal, confinement and post-natal care. Certain maternity beds have been reserved for them in hospitals and maternity homes. Lastly, there is a special provision requiring employers to provide immediate necessary medical treatment in case of any serious accident. They can be reimbursed the expenses incurred, subject to certain conditions.

The employment injury benefits are of three types temporary disablement benefit, permanent disablement benefit and dependents' benefit. If a person unfortunately sustains an injury in the course of and arising out of his employment, he will be entitled to the appropriate disablement benefit in cash. In capacity resulting from scheduled occupational diseases will also be treated as though it were an employment injury.

\section{BENEFITS IN CASH}

Temporary disablement cash henefit is payable till the disability is cured or the disablement can be assessed as a permanent one. Where permanent disablement occurs, the benefit is payable for life as a pension. Dependents' benefit is payable as pensions to his dependents if an insured person dies of an employment injury. The pension to the widow is paid till death or remarriage and to children till the age of 15 , or, if education continues, till the age of 18 . In case an insured person does not leave any surviving widow or children, this benefit can be paid to other dependents of the deceased.

As to the amount of cash benefits. it is ordinarily a little over half of the average daily wage. For total permanent disablement, the pension is payable at this full rate. For partial permanent disablement, a proportion of the full rate according to the degree of incapacity is paid as a pension. In denedents' benefit. the amount of the full rate is distributed to the dependents.

\section{GENEROUS PENSIONS}

I would like to emphasise here that the employment injury benefits under the State Insurance Scheme are a marked improvement on the provisions of the Workmen's Compensation Act. The pensions payable are comparatively generous. The periodical payments provide greater social security than lump sum payments which are likely to be soon exhausted, leaving the disabled person or the dependent unprovided for. Besides, as an injured person is entitled to free medical care, he is relieved of a heavy liability. The fact that the liability under the Workmen's Compensation Act is taken away from individual employers and placed on a public body ensures payment of employment injury benefits in all cases without any friction or inconvenience. There are other advantages which there is no time to mention to-night.

\section{SICKNESS BENEFIT}

There are two other types of benefits. One of them is sickness benefit and the other is maternity benefit. They are both paid in cash. Subject to certain contributory conditions, sickness cash benefit is available for a period of 56 days in any continuous period of 365 days and is at slightly over half the average daily wage In the event of her confinement. an insured woman is eligible to rash payment to the extent of 12 annas a day or the rate of sickness benefit. whichever is higher. This is payable for a period of 12 weeks of which not more than six weeks may precede the expested date of confinement. These two benefits are not available from the appointed day but will be available about nine months later. This period is necessary for two reasons. Firstly, since the benefits depend on payment of regular contributions in the contribution periods. and secondly to enable the contribution cards to be collected from employers after the periods are ended. This is essential in order to determine whether an employee has paid the requisite ndmber of contribntions. There are no such conditions attached to employment injury benefits and these are, therefore, available from the very beginning. It is recognised the world over that employment injury is the responsibility of the employer, as the risk arises specifically through employment, whereas that is not so in sickness and maternity. as the risk is spread over the living environment which contains an element of personal responsibility.

\section{REGIONAL，ORGANISATIONS}

Whereas the organisation of medical care is the responsibility of the State Government. the payment of cash benefits is the direct responsibility of the Corporation. For this purpose, a Regional Office of the Corporation has been set up in Bombay at Colaba. Twenty-four local offices are being set up all over the Greater Bombay area. At these local offices, insured persons will not only be able to put in their claims and receive payment but will also be able to obtain all information concerning their rights and responsibilities under the scheme. The Corporation has also brought out certain pamphlets to explain the Scheme to insured persons. These pamphlets will be available on request at the local offices of the Corporation.

The Scheme is administered at the Centre by a Corporation on which are represented employers, employees, the medical profession and the states. 
Without the co-operation of these interests, the Scheme cannot be a success. To ensure co-operation at the local level, regional boards and local committees will be set up in addition shortly.

Some of you may see one of our posters which depicts the five forms of benefit about which I have been talking to you this evening. The panch deep with its five flames which symbolise the benefits, will, I hope, serve as a constant reminder that social security, like all fields of human endeavour consists of both spirtual and material components and is, in principle, based on the nature, rights and dignity of man.

\section{(Reproduced from a SIS Press Service's Medical} Features dated 1st October 1954)

\section{A CASE OF MYSOPHOBIA}

Her neighbour were puzzled. They could understand why 37-year-old Mrs. H. B. should keep her house spotlessly clean, but they could not make out why sometimes she would get up in the middle of the night to do so.

When she refused to accept a cup of tea from friends, and when she was seen to scrub the door knobs after visitors had gone, the doctor was brought in. It did not take long to diagnose her condition as mysophobia, a morbid fear of contamination.

Such a persistent, abnormal fear is known as a phobia.

One authority has estimated that there are over 100 different phobias. Some of them are well-known because they have afflicted famous people.

The Italian dictator, Mussolini, for instance, suffered from a fear of confined spaces. This made him want to live in monstrously large rooms. This affliction is known as claustrophobia. The famous English writer, Samuel Johnson, was dominated by a morbid fear of death (thanatophobia).

More common is an irrational fear of disease. High blood pressure and cancer are favourite ailments of people with this phobia.

Normally, the bodily changes produced by fear are of relatively short duration-just long enough to help us to overcome a real or imagined threat. Fear sets off an alarm reaction which makes our nervous system 'wake-up' to the situation at hand. When the threat disappears. the bodv chemistry returns to normal.

But in the case of prolonged fear, whether caused by an emotional stress or a physical threat. changes in body chemistry may be so frequent and acute that they may threaten our health. For example, soldiers subjected to prolonged fighting-and thus prolonged fear and anxiety-underwent marked changes of the blood. These changes were so acute that they had previously only been observed in cases of extremely severe infection.

Often one of the body organs, usually the weakest link in our system, becomes affected. . Doctors know that fear causes the heart to race madly, and this can obviously aggravate a heart condition. Chromic fears have been known to set off ulcers. And fear is capable of producing changes in the skin.

The treatment of phobias is difficult. Experts believe they are the result of deep-rooted emotional problems which usually originated during early childhood.

The child's fear, they say, usually is symbolic of an inner conflict which he prefers not to face. For instance. a child may up in great fear of his father, whom he loves at the same time. The child, unable to avoid the presence of his father, may turn his fear toward something else that symbolises his father. Thus, as a substitute for the towering frame of his father. the child may develop an irrational fear of high places, or acrophobia.

In such a case, a person may overcome his phobia by being helped to recall and understand the painful memories which lie at the root of his obsessive fear. This has been accomplished sometimes by psychoanalysis.

But, particularly in far advanced cases, psychiatric treatment is not always enough. A person's phobias may have spread to take in more and more situations. until he finds himself unable to face everyday life.

Some years ago, Dr. Egas Moniz, a Portuguese Surgeon devised an operation to help the most hopeless patients. Known as prefrontal lobotomy, it involves severing the connection between the hrain's frontal lobes (the higher brain centres), and the rest of the braint. This makes the patient incapable of sufering fears and ${ }^{\mathrm{i}}$ anxieties. Opinion, however, is sharply divided on the benefits of this operation. Those opposed to it point' out that it also makes the patient incapable of being a responsible human being.

There is no ready-made solution for our countless phobias, ranging from agoraphobia (fear of wide open spaces) to triskaidekaphobia (dread of the number 13). And even the medical scientists, in their search for solutions, might get a mild case of what is perhaps the strangest of all phobias-phobophobia. This, believe it or not, is a dread of having a phobia! (ISPS)

\section{PREHISTORIC COCKROACH IS MODERN PEST}

Beware the cockroach. It is an insect with a long, long history and a great spreader of disease. It can be traced back scores of millions of years, to a period long before the appearance of the dinosaur. 